\title{
Incentivando alunas do Ensino Médio a Ingressarem em Carreiras de Ciência e Tecnologia na Paraíba
}

\author{
Ana Flávia S. A. Moura ${ }^{1}$, Thiago Henrique C. Tavares ${ }^{1}$, Giorgia de O. Mattos ${ }^{2}$, \\ Josilene A. Moreira ${ }^{2}$ \\ ${ }^{1}$ Discentes e ${ }^{2}$ Docentes do Centro de Informática - Universidade Federal da Paraíba \\ (UFPB) \\ Av. Dos Escoteiros, s/n - Mangabeira - 58055-000 - João Pessoa - PB - Brazil \\ anaflavia@eng.ci.ufpb.br, thiagoh.coelhotavares@gmail.com, \\ \{josilene, giorgia\}@ci.ufpb.br\}
}

\begin{abstract}
This paper resorts of the data obtained in a research carried out during two years in the extension project, in collaboration with high school girls from the public schools. The project has the intent of providing these students a first contact, through workshops, lectures and visits, with computer programming, promoting the female empowerment to the girls by education and awakening the interest to information technology as a reachable career path. Fear and the lack of interest of making use of new technologies are both hindrances caused by the privation of incentive, absence of widely known female representatives in the field of information technology, as well as the exclusion felt by women in both study and work environments.
\end{abstract}

Resumo. Este trabalho apresenta os dados obtidos em uma pesquisa realizada durante dois anos no projeto extensionista realizado junta às alunas do Ensino Médio da rede pública estadual. O projeto tem o intuito de proporcionar às alunas, por meio de oficinas, palestras e visitas, os primeiros contatos com a área de programação, promover o empoderamento feminino na educação bem como despertar o interesse pela tecnologia da informação para que esta seja considerada como possivel escolha profissional. Mostramse como empecilhos e medo e o desinteresse das alunas em usufruir de novas tecnologias devido à falta de incentivo, falta de modelos femininos de grande visibilidade na área, a exclusão sentida pelas mulheres tantos nos ambientes de estudos quanto de trabalho.

\section{Introdução}

A presença feminina na Computação vem diminuindo ao longo dos últimos anos. Tal desinteresse pela área pode ser explicado por fatores como a falta de modelos femininos de grande visibilidade na área, a exclusão sentida pelas mulheres tanto nos ambientes de estudo quanto de trabalho (normalmente dominado por homens) e a falta de incentivo para que sigam as carreiras ligadas à Computação [COOPER \& EDDY et al. 2010]. A Universidade Federal da Paraíba - UFPB - vem acompanhando esse cenário onde o ingresso de alunas mantem o baixo percentual, em torno de $14 \%$, nos três cursos da área de Ciência da Computação oferecidos pelo Centro de Informática.

A partir desta percepção, desde o ano de 2014 são conduzidos projetos de extensão (PROBEX e PROEXT) que trabalham na atração de mulheres para a área de Tecnologia da Informação. Várias estratégias vêm sendo adotadas com o intuito de 
promover a inclusão feminina, focadas principalmente na capacitação, incentivo e auxílio no desenvolvimento profissional de jovens alunas do ensino médio de escolas públicas. O projeto trabalha apresentando os cursos ofertados pelo Centro de Informática da UFPB, promovendo debates com temas relacionados à liberdade de escolha e atuação feminina em áreas consideradas masculinas dentro da Ciência e Tecnologia, especificamente na Computação, e ministrando oficinas lúdicas de estímulo à programação com a utilização de ferramentas digitais como Scratch, LightBot e MIT AppInventor. Neste relato, descrevemos as iniciativas utilizadas nos anos de 2016 e 2017 em duas escolas estaduais, Colégio da Policia Militar "Estudante Rebeca Cristina Alves Simões" e "Escola Técnica Estadual de João Pessoa Pastor João Pereira Gomes Filho".

\section{Metodologia}

O projeto foi realizado em duas escolas de ensino médio da rede pública, onde foram atendidas 74 alunas envolvidas no projeto. A equipe pedagógica é multidisciplinar, em parceria com profissionais das áreas de educação, psicologia, informática e engenharias. A abordagem inicial nas escolas foi feita através de palestras e debates promovendo a interação das alunas, professores e profissionais da área, difundindo as experiências de mulheres de destaque na área da ciência e tecnologia, bem como o relato de vivência de alunas de graduação. Após, foram preenchidos formulários, nos quais as alunas expressam seus interesses e opiniões pessoais referentes ao ingresso no ensino superior e suas atividades futuras. O perfil das alunas participantes foi identificado através de um questionário contendo perguntas sobre a sua expectativa em relação às oficinas, o grau de familiaridade com o computador e problemas de lógica computacional. Com todos estes dados foi possível analisar e identificar o grau de dificuldade das alunas bem como planejar as atividades e conteúdos a serem abordados.

Para estimular as alunas a conhecerem e escolherem os cursos das áreas de computação foram ministradas oficinas de desenvolvimento de aplicativos utilizando ferramentas computacionais como Lightbot, Code.org, Scratch e MIT App Inventor. Estas ferramentas utilizam a programação em blocos e estimulam o raciocínio lógico e computacional, introduzem conceitos básicos de programação e dão autonomia para que o desenvolvedor crie seus próprios aplicativos para Android e IOS de forma prática e divertida. Também foram proporcionados encontros extraclasse que permitiram que as alunas conhecessem o ambiente do Centro de Informática da UFPB, os laboratórios e projetos de pesquisa desenvolvidos em diversas áreas como modelagem computacional, inteligência artificial, robótica, eletrônica, entre outros, representando a ampla variedade de áreas dentro da computação em que elas podem atuar.

\section{Perfil das alunas participantes}

Os dados coletados através dos questionários foram tabulados com o objetivo de identificar as escolhas profissionais, familiaridade com a construção de algoritmos computacionais, nível de raciocínio lógico, traçar o perfil das alunas e assinalar quais os principais motivos para evitar as carreiras da área da ciência e tecnologia. Os resultados apresentados a seguir ilustram dados coletados durante a atuação do projeto no Colégio da Polícia Militar e Escola Técnica Estadual de João Pessoa nos anos de 2016 e 2017. 
Sobre o uso de computadores, celulares e internet a figura 1 mostra que $80 \%$ das entrevistadas pelo projeto possuem computador em casa, porém cerca de $36,5 \%$ nunca utilizam a máquina. Em paralelo, quando perguntado em relação ao uso de telefones celulares, todas declararam usar os aparelhos pelo menos entre 3 e 6 dias por semana e todas declararam acessar a internet. Disseram ainda que gastam grande parte de seu tempo online fazendo trabalhos escolares, buscando músicas e interagindo em redes sociais, $27,3 \%$ interagem em algum jogo online e apenas $18 \%$ disseram consumir jornais, revistas e outros periódicos online.
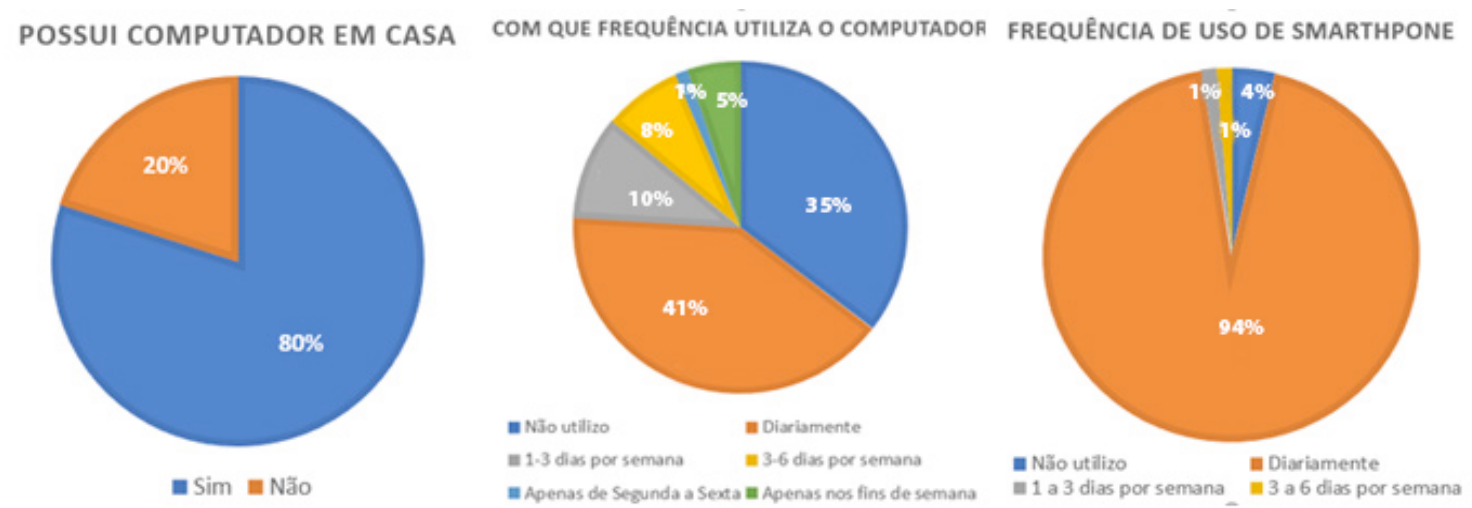

Figura 3. Frequência de uso de computador e smartphone.

No ano de 2017, foram incluídas no formulário questões a respeito das expectativas e interesse das alunas em relação ao projeto. Os resultados mostraram que apenas $10 \%$ das meninas possuíam algum conhecimento em lógica de programação ou programação de computadores, mas nenhuma delas havia de fato feito um programa de computador. Quando perguntado a respeito da expectativa do grau de dificuldade do curso proposto, no gráfico apresentado na figura 2, ficou clara a sensação de incapacidade e inaptidão que sentiam ao encarar novas tecnologias, 90,9\% responderam esperar que o curso fosse muito difícil, enquanto os $9,1 \%$ restantes avaliaram como nem fácil nem difícil.

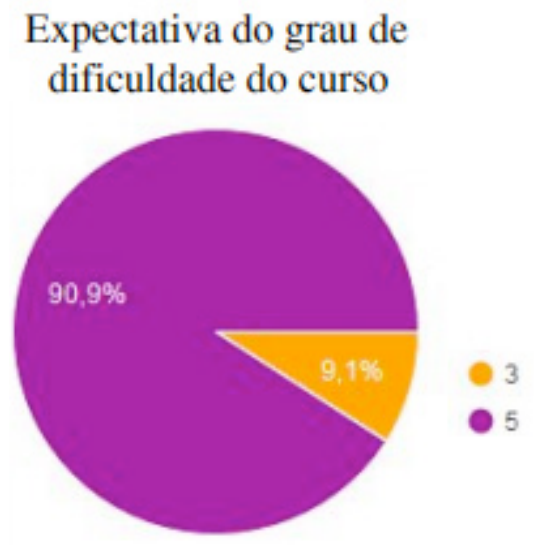

Figura 2. Expectativa do grau de dificuldade das alunas do ETE no ano de 2017

Em relação à motivação em participar das oficinas oferecidas, o gráfico apresentado na figura 3 , mostra a expectativa das alunas do CPM. O eixo Y indica o número de alunas, e no $\mathrm{X}$ indica a motivação das mesmas em fazer parte dos cursos. Enquanto $27 \%$ das alunas se sentiam pouco motivadas, o restante se dividia entre motivadas e muito motivadas. Ainda assim, quando perguntado o que esperavam obter 
como retorno das oficinas, a grande maioria respondeu que esperava aprender a programar, enquanto o restante gostaria de um melhor letramento digital.

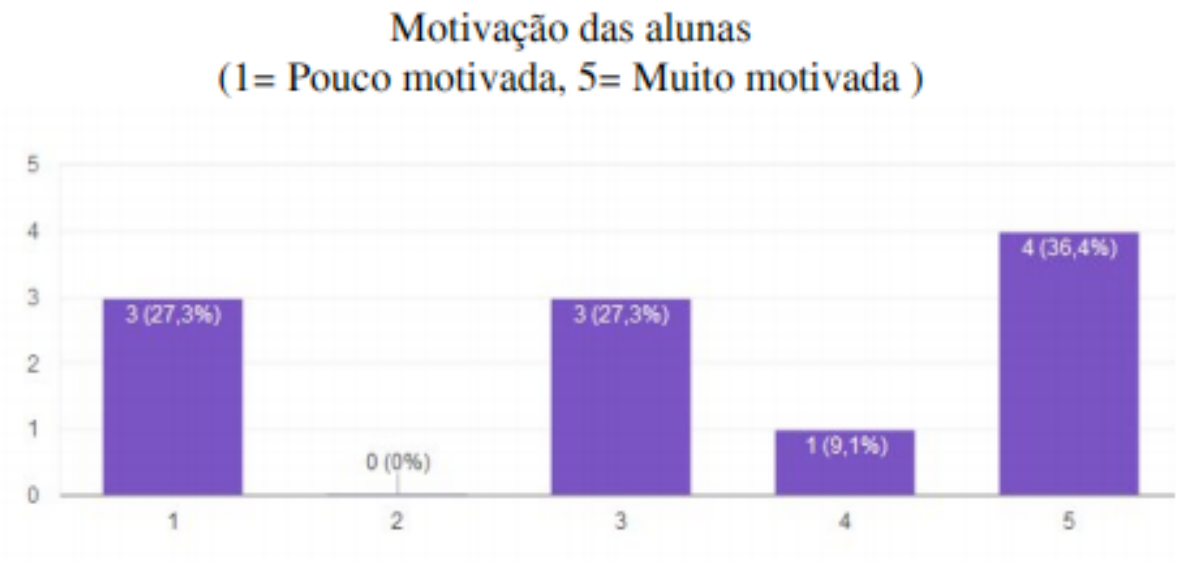

Figura 3. Motivação das alunas da ETE no ano de 2017

\section{Resultados}

Com relação ao uso de computadores, foi possível perceber que, ao mesmo tempo que a maioria declarou possuir computadores em casa, muitas disseram não aproveitar os recursos por medo ou simplesmente desinteresse, apenas utilizando as máquinas para o acesso nos fins de semana e majoritariamente para o acesso a redes sociais ou realização de trabalhos escolares. Tal desinteresse pela área pode ser explicado pela falta de modelos femininos de grande visibilidade na área. Souza et al $(2017$, p. 2) são incisivos nesse aspecto, a respeito da baixa participação e alto índice de desistência das mulheres na área de tecnologia, tanto no mercado de trabalho quanto em cursos acadêmicos. Com fator agravante, assinalam Sardina e Maciel (2016, p. 4), "grande parte desses alunos de escolas públicas sentem-se em desvantagem frente aos alunos de escolas privadas. Alguns pensam que mesmo após o ingresso na universidade será difícil acompanharem o curso, por disporem de menores recursos financeiros."

Em decorrência da participação no projeto, em um ambiente menos hostil e sem a opressão de colegas do sexo masculino, as alunas apresentaram rapidamente uma maior afinidade no uso de dispositivos móveis (tablets e celulares), dada a evidente presença deles em suas rotinas. No decorrer das atividades, foi clara a desmistificação da informática como escolha de campo de estudo e trabalho. Netto et al (2017, p.3) aponta como aspecto importante a aprendizagem de forma prazerosa é real, através do emprego de ferramentas corretas, que podem gerar resultados relevantes, tornando o processo imensamente produtivo. Diante das tarefas mais práticas, e ao ver figuras históricas femininas de grande importância para a área, as meninas se sentiam mais à vontade para aprender e produzir.

De acordo com depoimentos das alunas ficou clara a importância do alfabetismo digital, independente da área ou carreira que elas pretendem seguir. Constatou-se ainda que a programação e a construção de algoritmos beneficiou o raciocínio lógico, refletindo na melhora do entendimento de disciplinas obrigatórias como na matemática e na produção textual. Ao término do projeto algumas alunas relataram a mudança de pensamento, considerando a computação como uma real possibilidade de escolha profissional. 


\section{Conclusão}

Este relato descreveu as atividades desenvolvidas em escolas de rede pública com o objetivo de incentivar alunas do ensino médio a considerarem a área de computação também como possível escolha profissional. Os dados coletados durante o período de dois anos mostraram que mesmo antes de conhecerem de fato a programação de sistemas, as alunas já consideram a atividade difícil, podendo indicar um fator negativo no momento de escolher a sua futura profissão. Apenas $10 \%$ delas já tem um conhecimento prévio sobre lógica de programação o que dificulta o seu entrosamento com a tecnologia. Dentre as alunas que possuem computador quase a metade delas não o utilizam, evidenciando o pouco interesse e conhecimento da área.

Dentre as alunas participantes do projeto, após comprovada suas capacidades de aprendizado por meio de construção de aplicativos, uso de ferramentas e conhecimento da importância da mulher na história da ciência e computação, a maioria mudou de pensamento sobre a real possibilidade de ingresso nos cursos da área de tecnologia da informação no decorrer das oficinas. Segundo depoimentos das mesmas a programação e a construção de algoritmos beneficiou no raciocínio lógico e no pensamento computacional.

Os resultados mostram que, em ambientes e situações em que as alunas se sentem confortáveis e motivadas para o aprendizado, é possível reverter o quadro de desinteresse percebido em contatos iniciais, tornando a ciência da computação e áreas afins atrativas como opções de estudo e carreira.

\section{Referências}

Gnilka, P. B., Novakovic, A. (2017) Gender Differences in STEM Students Perfectionism, Career Search Self-Efficacy, and Percepction of Carrer Barriers. Journal of Counseling \& Development, v. 95, n. 1, p. 56-66.

Cooper, J., Eddy, P., Hart, J. Lester, J., Lukas, S., Eudey, B., Glazerraymo, J, Madden, M. (2010) "Improving gender equity in postsecondary education". In: Klein, S. S. (Gen. Ed.). Handbook for Achieving Gender Equity through Education, 2. ed., New York and London: Routledge, p. 631-653.

Souza, A. C. M., Perkoski, I., Viega, K., Romanki, V. (2017) "Relato Tech Ladies: redes de colaboração entre mulheres na tecnologia", http://csbc2017.mackenzie.br/public/files/11-wit/12.pdf, março.

Sardina, I. M., Maciel, C. (2016) "Ações para Incentivar Meninas do Ensino Médio a Cursar Carreiras Tecnológicas da Universidade Federal do Rio Grande do Norte", http://ebooks.pucrs.br/edipucrs/anais/csbc/assets/2016/wit01.pdf, abril.

Netto, D., Medeiros, L. M., Pontes, D., Morais, E. (2017) "Game Logic: Um jogo para auxiliar na aprendizagem de lógica de programação", http://csbc2017.mackenzie.br/public/files/25-wei/22.pdf, abril. 